\title{
Alergia ocupacional en el cultivo del melocotón
}

Occupational allergy related to peach cultivation

\author{
María Luisa Somoza ${ }^{1}$ (1) 0000-0002-0141-8914
}

${ }^{1}$ Hospital Universitario Infanta Leonor, Madrid, España.

Fechas - Dates

Recibido: 15/11/2021

Aceptado: 20/11/2021

Publicado: 17/01/2022
Sección coordinada por · Section coordinator

Dr. Guillermo García González

Correo electrónico: guillermo.garcia@unir.net 


\section{Entrevista a María Luisa Somoza}

¿Cuál es la procedencia, especialización y áreas de trabajo de los autores del artículo? ¿Qué características le parecen más destacables de este grupo de trabajo?

Lo más destacable es que se trata de un grupo multidisciplinar del que forman parte médicos especialistas en alergología, investigadores básicos, profesores de universidad y profesionales de I+D. Gracias a esta interacción, el trabajo se enriquece con las diversas aportaciones de cada uno de ellos, hechas desde diferentes áreas del conocimiento científico.

\section{¿Cómo se ha financiado el estudio?}

El estudio se ha financiado en su mayoría mediante fondos públicos a través de proyectos nacionales de investigación en salud (FIS), redes temáticas de Investigación Cooperativa en Salud (RETICS), ayudas para investigación de la fundación de la sociedad española de alergología e inmunología clínica (SEAIC), así como financiación privada.

¿Qué problema pretende abordar este estudio y dónde radica su interés o relevancia para la seguridad y salud en el trabajo?

España es el tercer país productor del mundo de melocotón después de EE.UU. y China. La mayor parte de la extensión de cultivo en España está dedicado a la producción de este fruto.

Somos el primer grupo que ha demostrado la importancia del polen de melocotonero como causante de alergia ocupacional, incluso hemos identificado el primer alérgeno inhalante más relevante (Pru p 9).

De este modo, podemos diagnosticar de forma precisa esta enfermedad en trabajadores expuestos con síntomas.

¿Qué aporta este estudio de novedoso o destacable en relación al resto de producción científica sobre el problema estudiado?

Hemos descubierto que este polen a pesar de ser mayoritariamente entomófilo, también se comporta como otros pólenes clásicos anemófilos, siendo incluso el tercero más frecuente en sensibilización en la zona de estudio (Murcia) después del polen de olivo y gramíneas.

¿Se han encontrado con alguna dificultad o contratiempo para el desarrollo del estudio?

Siempre, lo más difícil en un proyecto es conseguir financiación para poder llevarlo a cabo.

Además, en el último año, no hemos podido avanzar en su desarrollo debido a la situación de pandemia por COVID-19. 
¿Se han obtenido los resultados esperados o se ha producido alguna sorpresa?

Esta publicación es parte de un estudio de base poblacional cuyos resultados nos dirigieron hacia el estudio del polen de melocotonero como sensibilizador en trabajadores expuestos.

\section{¿Cómo ha sido el proceso de publicación? ¿Han sufrido alguna incidencia?}

Como en todas las publicaciones, el artículo final, es consecuencia de un trabajo constante y un equipo dedicado, en donde un descubrimiento te lleva a formar una nueva hipótesis a estudiar.

\section{¿Qué implicaciones tiene este estudio para la prevención de riesgos laborales? ¿Cuál sería la recomendación para mejorar la práctica profesional en relación al problema estudiado?}

En poblaciones expuestas, el test diagnóstico con polen de melocotonero debería incluirse, en la práctica clínica, de rutina al evaluar a sujetos con rinoconjuntivitis y/o asma.

\section{Resumen $^{(1)}$}

Anteriormente, varios trabajos han estudiado la importancia del melocotonero como fuente de alérgenos ocupacionales. Nuestro grupo ha identificado a un alérgeno (Pru p 9) del polen de melocotonero como responsable de síntomas de rinoconjuntivitis y asma en trabajadores expuestos.

Para ello, hemos incluido a 21 casos de la región del valle de Ricote en Murcia, quienes referían síntomas trabajando en las plantaciones durante la floración de dicho frutal. A todos ellos les realizamos un cuestionario, pruebas cutáneas alergológicas (prick test), pruebas de provocación nasal con el extracto de polen de melocotonero y Pru p 9 y técnicas "in vitro" como electroforesis e inmunotransferencia.

Como resultado, demostramos por primera vez que Pru p 9, un alérgeno del polen de melocotonero, puede inducir síntomas respiratorios en trabajadores expuestos y debe considerarse un alérgeno relevante cuando sujetos de estas plantaciones desarrollan rinoconjuntivitis y/o asma.

\section{Bibliografía}

1. Victorio-Puche L, Pérez-Sánchez N, Somoza ML, et al. Prunus persica 9, a new occupational allergen from peach tree pollen involved in rhinitis and asthma. Occup Environ Med. 2021;78(2):142-144. doi: 10.1136/oemed-2020-106641 